\title{
A descriptive study on the functioning profile of patients with spinal cord injury in a rehabilitation center in Russia
}

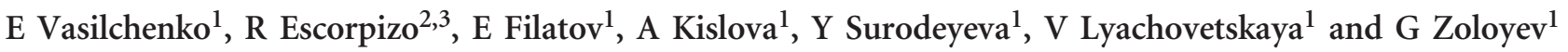

Study design: This is a cross-sectional study.

Objectives: (1) To use the International Classification of Functioning, Disability and Health (ICF) profile to assess the functioning of patients with spinal cord injury (SCI) admitted to a rehabilitation center; (2) To determine the role of the ICF in the operation of a rehabilitation center in Russia.

Setting: This study was conducted in the Federal center for disability rehabilitation in Novokuznetsk, Russia.

Methods: Eighty-one patients with SCl (59 men and 22 women; 31 with cervical, 41 with thoracic and 9 with lumbar level of injury) were included in the study. We determined the odds ratios of more pronounced impairments in ICF categories according to the duration of $\mathrm{SCl}$ and degree of neurological deficit.

Results: Mean age of patients was 34.9 \pm 11.1 years, men/women ratio was 2.7:1 and the median of time from injury was 2.5 (1.5-6) years. On the basis of American Spinal Injury Association Impairment Scale (AIS), most patients had AIS A ( N=31, 38.3\%). Patients with tetraplegia and AIS A or AIS B were at risk for more significant impairments in b620 'urination functions' and b640 'sexual functions'. Patients with paraplegia and AIS A or AIS B were at risk for more significant impairments in b735 'muscle tone functions'. Conclusion: Using the ICF, we were able to describe the range and extent of functioning problems experienced by patients with SCl who were admitted in our rehabilitation center. Moreover, the use of the ICF improved the interaction between specialists.

Spinal Cord (2017) 55, 489-496; doi:10.1038/sc.2016.120; published online 16 August 2016

\section{INTRODUCTION}

Spinal cord injury (SCI) is a leading cause of disability, and it represents a significant societal problem because of its increasing incidence and the high cost associated with the treatment of the patients. ${ }^{1,2}$

According to scarcely available epidemiological studies in Russia, the incidence of spinal trauma in large Russian industrial cities is 5-6 per $100000,{ }^{3,4}$ with $8000-8500$ new SCI cases every year. Subsequently, the number of people with disabilities due to SCI also increases; for example, there were 250000 individuals with SCIrelated disability in Russia in $2006{ }^{4}$

SCI can cause major impairments in basic physiological processes and body functions (impaired motor function, urinary tract, bowel, sexual function and respiratory function, as well as metabolic disorders). In addition, it affects the quality of life, both of the patient and the patient's family and caregiver. With these negative consequences of SCI, mitigating steps are necessary to improve an individual's daily life.

The development in rehabilitation medicine has brought about a reduction in mortality after SCI and an increase in the life span and quality of life of patients, which highlights the importance of a comprehensive rehabilitation for this group of patients and delivery of rehabilitation services. ${ }^{5}$
The Federal Centre for Disability Rehabilitation in Novokuznetsk, Russia provides comprehensive rehabilitation to patients with SCI. Services include reconstructive surgery of the spine, spinal cord and bladder; surgery for pressure sores; pharmacotherapy; therapeutic exercises; massage and physical therapy; and patient education in terms of self-care and ambulation skills. A multidisciplinary team consisting of surgeons, neurologists, physical therapists, psychologists, nursing staff and social workers are involved in the rehabilitation process.

Most patients with SCI receive multiple courses of treatment and rehabilitation in the Centre. The length of their hospital stays is limited by the standards of the sickness funds regarding the duration of, and payment for, a case of rehabilitation for a patient with SCI; the mean length of stay ranges from 21 to 28 days. Therefore, it is important to properly define both long-term and short-term rehabilitation goals (short-term goals being those of the current hospital admission) so that the appropriate hospital resources can be used more effectively and specific complications of SCI can be treated timely and properly. Another important issue is the mutual understanding and effective interaction between members of the multidisciplinary team, especially between medical and non-medical personnel. Non-medical personnel refer to specialists with nonmedical education such as those with legal or pedagogical education.

\footnotetext{
${ }^{1}$ Neurosurgical Department, Federal State Budgetary Scientific and Practical Centre for Medical and Social Evaluation and Rehabilitation of Disabled Persons in Novokuznetsk, Ministry of Labour and Social Protection of the Russian Federation, Novokuznetsk, Russian Federation; ${ }^{2}$ Department of Rehabilitation and Movement Science, University of Vermont, Burlington, VT, USA and ${ }^{3}$ Swiss Paraplegic Research, Nottwil, Switzerland

Correspondence: Associate Professor E Vasilchenko, Neurosurgical Department, Federal State Budgetary Scientific and Practical Centre for Medical and Social Evaluation and Rehabilitation of Disabled Persons in Novokuznetsk, Ministry of Health and Social Protection of the Russian Federation, Malaya street 7 , Novokuznetsk 654055, Kemerovo, Russian Federation.

E-mail: root@reabil-nk.ru

Received 19 July 2015; revised 23 June 2016; accepted 28 June 2016; published online 16 August 2016
} 
Defining rehabilitation goals should be based on a profound understanding and a thorough study of the problems related to the functioning of patients with SCI. ${ }^{6}$ At present, the International Classification of Functioning, Disability and Health (ICF) of the World Health Organization (WHO) is considered to be a universal reference framework to assess functioning and disability in light of health condition. The ICF has been used in understanding and examining the impact of SCI on the functioning of individuals with SCI. The ICF permits to perform a quantitative evaluation of impairments in body structure and body function, activity limitation and participation restriction with consideration to functioning and disability. ${ }^{7}$ Using an ICF-based functioning profile (ICF profile), we are able to describe the functional status of an individual and guide the development of rehabilitation goals and intervention targets. ${ }^{6,8}$

There has been no systematic study in understanding the functioning of people with SCI in Russia, and, moreover, the utility of the ICF in particular has not been demonstrated. Hence, this study has two objectives: (1) to demonstrate the utility of the ICF profile to assess the functioning of patients with SCI admitted to our rehabilitation center to improve functional outcomes; and (2) to explore the role of ICF-based approach in the operation of a rehabilitation hospital in Russia.

\section{MATERIALS AND METHODS}

We recruited 81 patients in the postacute period of SCI (at least 4 weeks after SCI) who were admitted to the Department of Neurosurgery of the Federal Center of Disability Rehabilitation of Novokuznetsk, Russia from August 2012 to June 2014 to receive a course of conservative treatment including drug therapy, physical therapy, therapeutic exercises and psychological intervention. Intensive care therapy in this group of patients during this hospitalization was not performed. Altogether, 930 patients with traumatic SCI were hospitalized during this period; 358 of them received surgical treatment, 572 received conservative treatment and the final number of patients included in the study was 81 persons. Eleven cases were excluded with some clinical and examination data (for example, data on psychologist intervention, physical exercises and so on) missing because some of the patients were discharged before completion of the study, or got worse and thus they could not continue to participate in the current study. This was found to be inapplicable because of the absence of different data sections. Compared with the group of patients who received rehabilitation treatment, the selection was representative in gender, age, spinal cord injury level and American Spinal Injury Association Impairment Scale (AIS) grade. Major reasons for exclusion from the study were as follows: the presence of at least one of the exclusion criteria, patients' unwillingness to participate in the study and acute condition. The exclusion criteria were as follows: mental and cognitive disorders, acute infectious diseases, exacerbations of chronic urological infections, ischemic heart disease (functional class 3 or 4 ) and chronic cardiac insufficiency. Functional class 3 is defined as when pain appears in ordinary physical activities: walking and climbing one flight of stairs; functional class 4 is when pain appears in minimal physical activities and at rest.

We analyzed the patients in terms of distribution based on 'classes of disability'. In the Russian Federation, the class of disability is determined by a committee for medical and social evaluation and is based on the presence and severity of major impairments of body functions due to disease, trauma or deformity, and on the severity of limitations and restrictions in major vital activities of daily living. ${ }^{9}$ Major impairments of body functions include the impairments in psychological functions, language and speech functions, written, verbal and non-verbal communication, voice formation, sensory functions, mobility, blood circulation, respiration, digestion, excretion, hemopoiesis, metabolism, endocrine and immune functions, as well as impairments due to physical deformities. Major vital activities include the abilities to care for oneself, to ambulate independently, to orient oneself in time and space, to communicate, to control one's actions in everyday life, to learn new knowledge and skills and to work (that is, employment). The comprehensive assessment of various parameters characterizing the broad term of 'limitations' in major categories of functioning distinguishes three degrees of severity of those limitations. The first degree of limitation means that a person needs more time or uses assistive devices in performing a particular vital activity but is still able to perform the activity independently. The second degree means that a person needs regular assistance, whereas the third degree of limitation is when a person is unable to carry out a vital activity and needs assistance permanently.

On the basis of these degrees of limitations mentioned, Class I disability is established based on the presence of a health condition with a strongly pronounced and persistent impairment of body functions that leads to the third-degree limitation in one or more vital activities and necessitates 'social protection' for the person concerned. Social protection as defined by the government means the individual's right to a monthly monetary allowance, to tax remissions and to rehabilitation devices and medications paid for by the social insurance fund. Class II disability is associated with a health condition with a pronounced persistent impairment of body functions that leads to the second-degree limitation in one or more vital activities and also necessitates social protection for the person concerned. Last, establishing Class III disability is based on the presence of a health condition with a moderate persistent impairment of body functions that leads to the second-degree limitation in one or more vital activities and necessitates social protection. People under the age of 18 who have health conditions with moderate or pronounced impairments of body functions needing social protection are given the status of 'child with a disability'.

To assess the level of function, to identify the rehabilitation goals and to define the hospital-based rehabilitation interventions, we used a set of categories from the ICF that are applicable specifically to SCI. ${ }^{10-13}$ The ICF category set to be used in this study was compiled based on the ICF Core Set for chronic spinal cord injuries and also using some of the categories from the standard ICF list used in the Swiss Study of Spinal Cord Injury. ${ }^{10,13}$ Our set contained a total of 27 ICF categories including 11 categories on body functions, 4 on body structures and 12 on activity and participation. We chose the ICF categories that reflected the extent of impairments in body functions and structures, as well as the limitation and restriction in performing activities and participation seen in patients with SCI. These impairments and limitations could potentially be addressed or mitigated in a hospital setting.

We assessed the ICF categories in our study using different data sources. Data on the functional status of patients were obtained from interviews, clinical examinations by various specialists (neurosurgeon, neurologist, urologist, psychologist, and specialist on social adaptation) and studies including X-ray, electrical myography and magnetic resonance imaging. The level and completeness of injury were evaluated using the neurological level and AIS. ${ }^{14}$ The intensity of pain was assessed with a visual analog scale. The muscle tone was assessed with the Modified Ashworth Scale, ${ }^{15}$ and the muscle strength was assessed with the 6-point Lovett Scale. ${ }^{16}$ The severity of pressure sores was assessed with the Agency for Health Care Policy and Research classification (AHCPR classification)..$^{7}$ The upper extremity function was determined with the van Lieshout test for arm/hand function of persons with tetraplegia (VLT). ${ }^{18}$ We used the self-report version of Spinal Cord Independence Measure III (SCIM-SR) questionnaire and Spinal Cord Injury Secondary Conditions Scale (SCI-SCS) to assess functioning in the ICF components of body functions and activity and participation. ${ }^{19,20}$ Last, emotional functions were measured with the Mental Health Scale of the SF- $36 .{ }^{13}$ There was a complex process of setting the mentioned instruments in order to obtain evaluation reliability and validity. First of all, Russian versions of the instruments were used. All the instructions were perused by our specialists. Further, clinical trials were conducted. Cross-sectional tests of one and the same patient were conducted by different specialists; test-retest reliability method was used as well. The testretest reliability of SCIM, VLT and SF-36 questionnaires varied from 0.77 to 0.85 correlation for different scales. Moreover, standardized training and procedures were also observed by the different specialists to minimize variability in the assessment of impairments. A multidisciplinary team (neurosurgeon, neurologist, urologist, psychologist and specialist on social adaptation) discussed all the unraveled divergences and reached consensus on each point.

The data on the measurement instruments used are shown in Table 1.

We assumed that only clinically significant impairments in body functions, body structures and limitations in activity and participation are amenable for 
Table 1 Measurement Instruments used in the study population

\begin{tabular}{|c|c|c|}
\hline ICF code & ICF category title & Measurement instrument \\
\hline b130 & $\begin{array}{l}\text { Energy and drive } \\
\text { functions }\end{array}$ & $\begin{array}{l}\text { Rating scale fatigue from } 0 \text { to } 3 \text { (from } \\
\text { insignificant problem to chronic problem) }\end{array}$ \\
\hline b152 & Emotional functions & SF-36 Item 8 \\
\hline b280 & Pain functions & Visual Analog Scale \\
\hline b440 & Respiration functions & $\begin{array}{l}\text { SCIM-SR Item } 5 \\
\text { SCI-SCS Item } 14\end{array}$ \\
\hline b525 & Defecation functions & $\begin{array}{l}\text { SCIM-SR Item } 7 \\
\text { SCI-SCS Item } 8\end{array}$ \\
\hline b620 & Urination functions & $\begin{array}{l}\text { SCIM-SR Item } 6 \\
\text { SCI-SCS Item 7, } 9\end{array}$ \\
\hline b640 & Sexual functions & SCI-SCS Item 10 \\
\hline b710 & Joint mobility functions & SCI-SCS Item 4 \\
\hline b730 & $\begin{array}{l}\text { Muscle strength } \\
\text { functions }\end{array}$ & Lovett Scale \\
\hline b735 & Muscle tone functions & $\begin{array}{l}\text { Modified Ashworth Scale } \\
\text { SCI-SCS Item } 3\end{array}$ \\
\hline $\begin{array}{l}\text { b810 } \\
\text { s810 }\end{array}$ & $\begin{array}{l}\text { Protective functions of } \\
\text { the skin } \\
\text { Structure of the skin }\end{array}$ & AHCPR classification \\
\hline s120 & $\begin{array}{l}\text { Spinal cord and related } \\
\text { structures }\end{array}$ & AIS \\
\hline s430 & $\begin{array}{l}\text { Structure of the respira- } \\
\text { tory system }\end{array}$ & SCIM-SR Item 5 \\
\hline s610 & $\begin{array}{l}\text { Structure of the urinary } \\
\text { system }\end{array}$ & SCIM-SR Item 6 \\
\hline $\mathrm{d} 410$ & Body posture change & SCIM-SR Item 9 \\
\hline $\mathrm{d} 420$ & Body transfer & SCIM-SR Items 10, 11 \\
\hline $\mathrm{d} 445$ & Use of the hand & VLT \\
\hline $\mathrm{d} 450$ & Walking & SCIM-SR Items 12-14 \\
\hline $\mathrm{d} 465$ & Transfers using devices & SCIM-SR Items 12-15 \\
\hline $\mathrm{d} 470$ & Use of transport & SCIM-SR Item 16 \\
\hline d510 & Washing oneself & SCIM-SR Item 2 \\
\hline d520 & Caring for body parts & SCIM-SR Item 4 \\
\hline d530 & Toileting & SCIM-SR Item 8 \\
\hline d540 & Dressing & SCIM-SR Item 3 \\
\hline d550 & Eating & SCIM-SR Item 1 \\
\hline d560 & Drinking & \\
\hline
\end{tabular}

Abbreviations: AHCPR classification, Agency for Health Care Policy and Research classification SF-36, Medical Outcomes Study Short Form-36; SCIM-SR, self-report version of Spinal Cord Independence Measure III; SCI-SCS, Spinal Cord Injury Secondary Conditions Scale; VLT test, Van Lieshout Test for arm/hand function of persons with tetraplegia.

intervention in a hospital setting. Therefore, slight impairments (that is, ICF Qualifier 1) are not presented in the results section of this article.

\section{Statistical analysis}

Numerical variables are expressed as mean with standard deviation or median (with 25th and 75th percentile) depending on the normality of the data distribution. For categorical variables, absolute numbers and percentages are shown. The $\chi^{2}$ test was used to check the statistical hypotheses regarding differences in absolute and relative frequencies, proportions and ratios between two independent samples. Correlation analysis was done with the Spearman's rank correlation coefficient. We also performed univariate logistic regression. We used the ICF categories in the dichotomous format as dependent variables. The degree of impairments in the ICF categories assumed two values: with a problem or without a problem. Further, we used the level of neurological deficit based on AIS grade (A and B versus C and D) as an independent variable. The division of patients into these two groups was based on a preliminary analysis that did not show any significant differences in the frequency of problems either between patients with AIS A and those with AIS B or between those with
AIS C and those with AIS D. Another independent variable was the duration of SCI. To choose the cutoff point, we analyzed sensitivity and specificity for the ICF categories (b710, d410, d420, d445, d465, d510, d530, d550 and d560) for the SCI durations of up to 1 year and over 1 year, up to 1.5 years and over 1.5 years, and up to 2 years and over 2 years. The optimal cutoff point was found to be 2 years. Sensitivity for this cutoff point varied from 0.57 to 0.80 , and specificity from 0.61 to 0.72 . The null hypothesis was rejected if $P$ value was below 0.05 .

The data were processed using the standard STATISTICA package (Version 10.0.1011.0, StatSoft Russia, Moscow, Russia).

\section{Ethics}

Approval for this study was obtained from the Ethics Committee of the Scientific and Practical Centre for Medical and Social Evaluation and Rehabilitation of Disabled Persons in Novokuznetsk, Russia. All participants provided written informed consent to participate in the study.

\section{RESULTS}

\section{Sample characteristics}

The majority of patients were male $(73 \%)$ with a mean age of $34.9 \pm 11.1$ years. The median of time from injury was 2.5 years (Table 2).

Most of the patients had a class I level of disability (87.7\%). The most common causes of SCI were transportation-related activities. Notably, sports and leisure activities were a leading causes of SCI only in men $(25.4 \%)$, whereas not a single injury in women was associated with it.

Injury at the thoracic spine level was the most common form of injury $(50.6 \%)$, whereas $38.3 \%$ of the patients had injury at the cervical level, and $11.1 \%$ at lumbar level.

\section{ICF functioning profile}

The results of the assessment of impairments in body function and body structure, and limitation in activities and restriction in participation, are summarized in Table 3. It shows the absolute and relative frequency of the different extents of impairments in the ICF categories seen in patients with SCI in our sample. We did not classify the patients by the level of neurological deficit or gender in this table.

\section{Analysis of relationships between disability per ICF and independent factors}

There were weak but significant relationships between patients' age and the extents of impairments in the body function category of b280 'pain functions', meaning that older patients experienced more intense pain (Table 4).

There were either weak or moderate negative correlations between the duration of SCI and the severity of limitation in the body function categories of b152 'emotional functions', b730 'muscle strength functions' and b810 'protective functions of the skin'. Negative relationships were also seen between the duration of SCI and the activities and participation, and these relationships were strongest for the categories d420 'body transfer' and d465 'transfers using devices'. This means that the severity of limitations in some ICF categories of body function and body structures and activities and participation decreases as the duration of SCI increases.

We found positive relationships between the degree of neurological deficit (AIS) and the extent of impairments in body functions and structures, as well as activity and participation, for the ICF categories of b525 'defecation functions', b620 'urination functions', b640 'sexual functions', b730 'muscle strength functions', b735 'muscle tone functions', s120 'spinal cord and related structures', s610 'structure of the urination system', d410 'body posture change', d420 
Table 2 Characteristics of the study population

\begin{tabular}{ll}
\hline Parameters & \\
\hline Total sample, no. (\%) & $81(100 \%)$ \\
Male, N (\%) & $59(72.8 \%)$ \\
Age, years mean \pm s.d. (range) & $34.9 \pm 11.1(16.2-62.2)$ \\
& \\
Class of disability no. (\%) & $5(6.2 \%)$ \\
O (not established) & $71(87.7 \%)$ \\
I & $3(3.7 \%)$ \\
II & $1(1.2 \%)$ \\
III & $1(1.2 \%)$ \\
Child with a disability & \\
Cause of SCI, N (\%) & \\
Sports and leisure activities & $15(18.6 \%)$ \\
Assaults & $1(1.2 \%)$ \\
Transport activities & $36(44.4 \%)$ \\
Falls & $21(25.9 \%)$ \\
Other traumatic causes & $8(9.9 \%)$ \\
Nontraumatic causes & 0 \\
Unknown & 0 \\
Duration of SCI (years), median (25th and 75th & $2.5(1.5-6), 1$ month to 27 \\
percentile) range & years \\
Level of SCI, N (\%) & \\
Cervical & \\
Thoracic & $31(38.3 \%)$ \\
Lumbar & $41(50.6 \%)$ \\
AlS Classification, N (\%) & $9(11.1 \%)$ \\
A & \\
B & $31(38.3 \%)$ \\
D & $15(18.5 \%)$ \\
\hline A & $24(29.6 \%)$ \\
& $11(13.6 \%)$ \\
\hline
\end{tabular}

Abbreviations: AIS, American Spinal Injury Association Impairment Scale; SCI, spinal cord injury.

'body transfer', d450 'walking' and d470 'use of transport'. There were no significant relationships between gender and any of the ICF categories (Table 4).

\section{Analysis of impairments and limitation based on duration of SCI} We found that patients with tetraplegia and duration of SCI of more than 2 years were at risk of more significant impairments in the ICF categories of b710 'joint mobility functions' (odds ratio (OR): 6.5 (95\% confidence interval (CI): 1.09-38.63)), d410 'body posture change' (OR: 6.5 (95\% CI: 1.09-38.63)), d445 'use of the hand' (OR: 6.5 (95\% CI: 1.09-38.63)), d550 'feeding' (OR: 6.67 (95\% CI: 1.31-33.69)) and d560 'drinking' (OR: 6.67 (95\% CI: 1.31-33.69)). Those with paraplegia and durations of SCI of more than 2 years were at risk of more significant problems in d420 'body transfer' (OR: 6.9 (95\% CI: 1.83-25.96)), d465 'transfers using devices' (OR: 3.5 (95\% CI: 1.05-11.48)), d510 'washing oneself (OR: 3.5 (95\% CI: 1.07-11.48)) and d530 'toileting' (OR: 3.36 (95\% CI: 1.01-11.11)) (Table 5).

There was a positive relationship between the duration of SCI and the body function category b280 'pain functions', meaning that pain becomes more intense as the duration of SCI increases.

\section{Analysis of impairments and limitation based on extent of} neurological deficit

Patients with tetraplegia and AIS A or AIS B were found to be at risk of more significant impairments in the ICF categories of b620 'urination functions' (OR: 23.33 (95\% CI: 2.41-225.22), b640 'sexual functions' (OR: 30 (95\% CI: 3.03-296.6), b730 'muscle strength functions' (OR: 11.92 (95\% CI: 2.18-65.15), d420 'body transfer' (OR: 6.13 (95\% CI: 1.02-36.89)) and d445 'use of the hand' (OR: 14 (95\% CI: 2.25-87.2)). Those with paraplegia and AIS A or AIS B were at risk of more significant impairments in b620 'urination functions' (OR: 9.67 (95\% CI: 1.03-90.04)), b640 'sexual functions' (OR: 12.11 (95\% CI: 2.98-48.82)), b730 'muscle strength functions' (OR: 7.94 (95\% CI: 2.01-31.34)) and b735 'muscle tone functions' (OR: 23.7 (95\% CI: 2.68-209.78)) (Table 6).

\section{DISCUSSION}

Despite the high level of individual and societal burden of SCI, there is a lack of descriptive data on the functioning and disability of people with SCI in Russia. An initial step toward identifying SCI-related burden is by using the universal framework on functioning (that is, ICF of the WHO). This study provides a descriptive set of data on a group of patients with SCI who were admitted to a rehabilitation center located in Russia. The burden of SCI was evident in our study in terms of prevalent and high-level impairment in body functions and body structures, and limitation and restrictions in activity and participation after SCI. This study can be used to guide future studies in Russia to prioritize target areas for intervention that affect individual functioning the most and in examining healthcare services provided to people with SCI.

Comparing our results within Russia is difficult because of the lack of available published data. However, we can discuss and compare our study with studies in the existing literature. On the basis of our study, the two most common causes of SCI included transport activities and falls; for comparability, these were also the leading causes of SCI in some studies performed in other countries. ${ }^{21,22}$ Men were affected with SCI more often, and the men/women ratio was 2.7:1. This finding is comparable to the data from studies conducted in the Netherlands, Turkey, Taiwan, Portugal and China. ${ }^{23-27}$ By analyzing the age distribution of patients, we found that SCI occurred most often in the age group 16-30 years (45.7\%), which was followed by the group $31-45$ years $(33.3 \%)$. Studies in China and Nigeria found the age group 31-45 years to be the one that was affected most frequently, ${ }^{21,26}$ whereas in a Japanese study it was the 65 and over age group. $^{28}$

Patients with SCI in our sample are mainly young men who have been injured because of transport activities, falls or sports and leisure activities. Until recently, the drivers of personal motor vehicles in Russia were mostly male. Many young men tend to exceed the speed limits when driving. Besides, not all the automobiles used in Russia are equipped with airbags, which contributes to the lack of safety. Failure to follow safety rules is also the reason why many men sustain SCI when diving in rivers or lakes.

With regard to the distribution of patients by the level of injury, we found that SCI occurred most often in the thoracic spine (50.6\%). Cervical and lumbar lesions were seen in 38.3 and $11.1 \%$ of cases, respectively. These proportions are similar to the findings described in an article about patients with SCI treated at the Turkish Army Forces Rehabilitation Center. ${ }^{23}$ In contrast, a Chinese study found that it was the cervical spine that was affected by SCI most often in their sample. ${ }^{26}$ 
Table 3 Frequency of the extent of disability in our sample based on ICF components

\begin{tabular}{|c|c|c|c|c|c|c|c|}
\hline \multirow{3}{*}{ ICF category } & & \multicolumn{6}{|c|}{ Numbers of patients with impairments (absolute frequency and percentage) } \\
\hline & & \multicolumn{6}{|c|}{ ICF qualifier } \\
\hline & & 0 & 1 & 2 & 3 & 4 & 8 \\
\hline \multirow[t]{2}{*}{ b130 Energy and drive functions } & $\mathrm{T}$ & $1(3.2)$ & $7(22.6)$ & $22(71)$ & $1(3.2)$ & 0 & 0 \\
\hline & $P$ & $6(12)$ & $11(22)$ & $28(56)$ & $5(10)$ & 0 & 0 \\
\hline \multirow[t]{2}{*}{ b152 Emotional functions } & $\mathrm{T}$ & $2(6.5)$ & $13(41.9)$ & $13(41.9)$ & $3(9.7)$ & 0 & 0 \\
\hline & $P$ & $8(16)$ & $11(22)$ & $27(54)$ & $4(8)$ & 0 & 0 \\
\hline \multirow[t]{2}{*}{ b280 Pain functions } & $\mathrm{T}$ & $14(45.1)$ & $2(6.5)$ & $12(38.7)$ & $3(9.7)$ & 0 & 0 \\
\hline & $P$ & $20(40)$ & $7(14)$ & $16(32)$ & $7(14)$ & 0 & 0 \\
\hline \multirow[t]{2}{*}{ b440 Respiration functions } & $\mathrm{T}$ & $27(87.1)$ & 4 (12.9) & 0 & 0 & 0 & 0 \\
\hline & $P$ & $44(88)$ & $5(10)$ & $1(2)$ & 0 & 0 & 0 \\
\hline \multirow[t]{2}{*}{ b525 Defecation functions } & $\mathrm{T}$ & $5(16.2)$ & $4(12.9)$ & $13(41.9)$ & $8(25.8)$ & $1(3.2)$ & 0 \\
\hline & $P$ & $12(24)$ & $13(26)$ & $19(38)$ & $6(12)$ & 0 & 0 \\
\hline \multirow[t]{2}{*}{ b620 Urination functions } & $\mathrm{T}$ & 0 & $10(32.3)$ & $10(32.3)$ & $10(32.3)$ & $1(3.1)$ & 0 \\
\hline & $P$ & $6(12)$ & $7(14)$ & $23(46)$ & $13(26)$ & $1(2)$ & 0 \\
\hline \multirow[t]{2}{*}{ b640 Sexual functions } & $\mathrm{T}$ & 0 & $3(9.7)$ & $8(25.8)$ & $6(19.3)$ & $14(45.2)$ & 0 \\
\hline & $P$ & $3(6)$ & $2(4)$ & $12(24)$ & $18(36)$ & $15(30)$ & 0 \\
\hline \multirow[t]{2}{*}{ b710 Joint mobility functions } & $\mathrm{T}$ & $18(58)$ & $3(9.7)$ & $7(22.6)$ & $3(9.7)$ & 0 & 0 \\
\hline & $\mathrm{P}$ & $40(80)$ & $5(10)$ & $2(4)$ & $3(6)$ & 0 & 0 \\
\hline \multirow[t]{2}{*}{ b730 Muscle strength functions } & $\mathrm{T}$ & 0 & $1(3.2)$ & $13(41.2)$ & $15(48.4)$ & $2(6.5)$ & 0 \\
\hline & $\mathrm{P}$ & 0 & $3(6)$ & $12(24)$ & $30(60)$ & $5(10)$ & 0 \\
\hline \multirow[t]{2}{*}{ b735 Muscle tone functions } & $\mathrm{T}$ & $0(0)$ & $2(6.5)$ & 7 (22.6) & $21(67.8)$ & 0 & $1(3.2)$ \\
\hline & $P$ & $1(2)$ & $9(18)$ & $18(36)$ & $22(44)$ & 0 & 0 \\
\hline \multirow[t]{2}{*}{ b810 Protective functions of the skin } & $\mathrm{T}$ & $25(80.1)$ & $1(3.2)$ & $4(12.9)$ & $1(3.2)$ & 0 & 0 \\
\hline & $P$ & $46(92)$ & $2(4)$ & $1(2)$ & $1(2)$ & 0 & 0 \\
\hline \multirow[t]{2}{*}{ s120 Spinal cord and related structures } & $\mathrm{T}$ & $0(0)$ & 0 & $15(48 / 4)$ & $8(25.8)$ & $8(25.8)$ & 0 \\
\hline & $P$ & 0 & 0 & $21(42)$ & $7(14)$ & $22(44)$ & 0 \\
\hline \multirow[t]{2}{*}{ s430 Structure of the respiratory system } & $\mathrm{T}$ & $28(90.3)$ & $3(9.7)$ & 0 & 0 & 0 & 0 \\
\hline & $P$ & $44(88)$ & $6(12)$ & 0 & 0 & 0 & 0 \\
\hline \multirow[t]{2}{*}{ s610 Structure of the urination system } & $\mathrm{T}$ & $21(67.7)$ & $2(6.5)$ & $5(16.1)$ & $3(9.7)$ & 0 & 0 \\
\hline & $P$ & $25(50)$ & $7(14)$ & $16(32)$ & $2(4)$ & 0 & 0 \\
\hline s810 Structure of the skin & $\mathrm{T}$ & $25(80.1)$ & $1(3.2)$ & 4 (12.9) & $1(3.2)$ & 0 & 0 \\
\hline & $P$ & $46(92)$ & $3(6)$ & 0 & $1(2)$ & 0 & 0 \\
\hline d410 Body posture change & $\mathrm{T}$ & $15(48.4)$ & $3(9.7)$ & $3(9.7)$ & $3(9.7)$ & $7(22.6)$ & 0 \\
\hline & $P$ & $31(62)$ & $15(30)$ & $1(2)$ & $3(6)$ & 0 & 0 \\
\hline d420 Body transfer & $\mathrm{T}$ & $6(19.4)$ & $3(9.7)$ & $8(25.8)$ & $2(6.5)$ & $12(38.7)$ & 0 \\
\hline & $P$ & $17(34)$ & $6(12)$ & $21(42)$ & $5(10)$ & $1(2)$ & 0 \\
\hline $\mathrm{d} 445$ Use of the hand & & 0 & $12(38.7)$ & $9(29)$ & $6(19.3)$ & 4 (12.9) & 0 \\
\hline & & $46(92)$ & $4(8)$ & 0 & 0 & 0 & 0 \\
\hline d450 Walking & & 0 & 0 & $1(3.2)$ & $8(25.8)$ & $22(71)$ & 0 \\
\hline & & 0 & $3(6)$ & $6(12)$ & $5(10)$ & $36(72)$ & 0 \\
\hline d465 Transfers using devices & $\mathrm{T}$ & 1 (3.2.) & $11(35.5)$ & $9(29)$ & $6(19.4)$ & $4(12.9)$ & 0 \\
\hline & $P$ & $15(30)$ & $9(18)$ & $20(40)$ & $2(4)$ & $3(6)$ & 0 \\
\hline $\mathrm{d} 470$ Use of transport & $\mathrm{T}$ & 0 & $3(9.7)$ & $7(22.6)$ & $4(12.9)$ & $16(51.6)$ & $1(3.2)$ \\
\hline & $P$ & $2(4)$ & $11(22)$ & $17(34)$ & $9(18)$ & $6(12)$ & $5(10)$ \\
\hline d510 Washing oneself & $\mathrm{T}$ & $2(6.5)$ & $4(12.9)$ & $6(19.4)$ & $10(32.3)$ & $9(29)$ & \\
\hline & $P$ & $12(24)$ & $17(34)$ & $13(26)$ & $7(14)$ & $1(2)$ & \\
\hline d520 Caring for body parts & $\mathrm{T}$ & $11(35.5)$ & $1(3.2)$ & $7(22.6)$ & $6(19.4)$ & $6(19.4)$ & \\
\hline & $P$ & $31(62)$ & $13(26)$ & $2(4)$ & $4(8)$ & 0 & 0 \\
\hline d530 Toileting & $\mathrm{T}$ & $5(16.1)$ & $3(9.7)$ & $8(25.8)$ & $5(16.1)$ & $10(32.3)$ & 0 \\
\hline & $P$ & $13(26)$ & $18(30)$ & $13(26)$ & $3(6)$ & $3(6)$ & \\
\hline d540 Dressing & $\mathrm{T}$ & $3(9.6)$ & 4 (12.9) & $5(16.1)$ & $9(29)$ & $10(32.3)$ & \\
\hline & $P$ & $28(56)$ & $14(28)$ & $3(6)$ & $3(6)$ & $2(4)$ & \\
\hline d550 Feeding & $\mathrm{T}$ & $9(29)$ & $9(29)$ & $5(16.1)$ & $4(12.9)$ & $4(12.9)$ & 0 \\
\hline & $P$ & $49(98)$ & 0 & $1(2)$ & 0 & 0 & \\
\hline d560 Drinking & $\mathrm{T}$ & $9(29)$ & $9(29)$ & $5(16.1)$ & $4(12.9)$ & $4(12.9)$ & 0 \\
\hline & $P$ & $49(98)$ & 0 & $1(2)$ & 0 & 0 & \\
\hline
\end{tabular}


Table 4 Data on correlation coefficients $(r)$ between gender, age, duration of $\mathrm{SCl}$, degree of neurological deficit and extents of impairments/limitations in the ICF categories

\begin{tabular}{|c|c|c|c|c|}
\hline ICF category & Age & $\begin{array}{c}\text { Duration } \\
\text { of } \mathrm{SCl}\end{array}$ & $\begin{array}{l}\text { AIS } \\
\text { grade }\end{array}$ & Gender \\
\hline b130 Energy and drive functions & 0.12 & -0.02 & -0.15 & 0.01 \\
\hline b152 Emotional functions & 0.08 & $-0.27^{\star}$ & -0.14 & -0.09 \\
\hline b280 Pain functions & $0.22 *$ & $0.25^{*}$ & -0.02 & 0.13 \\
\hline b440 Respiration functions & 0.07 & -0.02 & -0.13 & 0.03 \\
\hline b525 Defecation functions & -0.13 & -0.10 & $0.29 *$ & 0.01 \\
\hline b620 Urination functions & -0.15 & -0.06 & $0.43^{*}$ & 0.07 \\
\hline b640 Sexual functions & 0.04 & -0.02 & $0.55^{*}$ & -0.16 \\
\hline b710 Joint mobility functions & 0.14 & -0.22 & -0.06 & -0.22 \\
\hline b730 Muscle strength functions & $-0.22^{*}$ & $-0.22^{*}$ & $0.51^{*}$ & -0.01 \\
\hline b735 Muscle tone functions & -0.07 & -0.06 & $0.40^{*}$ & -0.16 \\
\hline b810 Protective functions of the skin & -0.08 & $-0.23^{*}$ & 0.06 & -0.15 \\
\hline s120 Spinal cord and related structures & -0.10 & 0.08 & $0.92 *$ & -0.04 \\
\hline s430 Structure of the respiratory system & 0.01 & -0.01 & -0.07 & 0.05 \\
\hline s610 Structure of the urination system & 0.11 & $-0.29 *$ & $0.27^{*}$ & 0.14 \\
\hline s810 Structure of the skin & -0.09 & -0.23 & 0.06 & -0.15 \\
\hline d410 Body posture change & -0.13 & $-0.30^{*}$ & $0.26^{*}$ & 0.06 \\
\hline d420 Body transfer & -0.13 & $-0.43^{*}$ & $0.23^{*}$ & -0.06 \\
\hline $\mathrm{d} 445$ Use of the hand & -0.16 & $-0.23^{*}$ & -0.02 & -0.27 \\
\hline d450 Walking & -0.21 & 0.07 & $0.55^{*}$ & -0.17 \\
\hline d465 Transfers using devices & 0.01 & $-0.41^{*}$ & 0.08 & -0.02 \\
\hline $\mathrm{d} 470$ Use of transport & 0.04 & -0.17 & $0.35^{*}$ & 0.03 \\
\hline d510 Washing oneself & -0.02 & $-0.41^{*}$ & 0.04 & -0.09 \\
\hline d520 Caring for body parts & 0.05 & $-0.35^{*}$ & 0.20 & -0.06 \\
\hline d530 Toileting & -0.03 & -0.38 & 0.21 & -0.14 \\
\hline d540 Dressing & 0.02 & $-0.27^{*}$ & 0.11 & -0.10 \\
\hline d550 Feeding & -0.13 & $-0.24^{*}$ & 0.05 & -0.22 \\
\hline d560 Drinking & -0.13 & $-0.24^{*}$ & 0.05 & -0.22 \\
\hline
\end{tabular}

Abbreviations: AIS grade: American Spinal Injury Association Impairment Scale grade; ICF, International Classification of Functioning, Disability and Health. ${ }^{*} P<0.05$.

By analyzing the distribution of patients, we found that the most common type of neurological deficit was AIS A (38.3\%), closely followed by AIS C (29.6\%). Complete damage to the spinal cord with loss of motor and sensory functions most often leads to severe or complete impairments in patients' functions and activities and participation.

The clinical and social consequences of SCI are described in numerous papers. Particularly, Nas et al. ${ }^{29}$ note that 'spasticity, neurogenic bladder and bowel, urinary tract infections, pressure ulcers, orthostatic hypotension, fractures, deep-vein thrombosis, autonomic dysreflexia, pulmonary and cardiovascular problems and depressive disorders are frequent complications after SCI. SCI leads to serious disability in the patient, resulting in the loss of work, which brings psychosocial and economic problems'.

In our study, the differences in the levels of functioning between patients with paraplegia and those with tetraplegia involved 11 ICF categories including protective functions of the skin, structure of the skin, joint mobility functions, use of the hand, body posture change and self-care activities. ${ }^{30}$ For these categories, impairments were more severe in patients with tetraplegia. The study by Hermann et al. also reported more significant impairments in the functioning of patients with tetraplegia. ${ }^{31}$ This is to be expected because of the higher level of impairment in tetraplegia, thus affecting multiple systems or organs of the body and multiple disabilities. For example, patients with tetraplegia may experience hand function deficits, respiratory problems and problems in communication that would not necessarily be present in patients with paraplegia. It should be noted that urination, defecation and sexual dysfunctions present in both tetraplegia and paraplegia categories of patients. As researches suggest, these dysfunctions significantly affect the quality of life of patients with SCI; hence, autonomic dysfunctions are a priority in the holistic management of SCI. ${ }^{32,33}$

The extents of impairments in functioning and activity and participation were related to the degree of neurological deficit, as measured by the AIS level. A larger neurological deficit meant more severe impairments in defecation, urination, sexual, muscle strength and muscle tone functions.

The presence of AIS A or AIS B neurological deficit markedly increases the risk of more severe impairments in body functions and activities and participation both in patients with tetraplegia and those with paraplegia. This risk is higher in patients with tetraplegia; increasing extent of neurological deficit increases the risk of problems with defecation functions, sexual functions, muscle strength, muscle tone, body transfer and use of the hand.

Both older age and longer durations of SCI were associated with more significant impairments in pain functions (b280). Patients with longer durations of SCI had less severe impairments in emotional, pain and muscle strength functions, as well as protective functions of the skin. In addition, these patients were less likely to have severe or complete impairments in ambulation and self-care. Patients with longer durations of SCI were better adapted with regard to transfers using devices. This observation may be because of adaptation of the individual person with SCI and/or improvement of function over time because of healthcare services and intervention provided.

Patients with tetraplegia and duration of SCI longer than 2 years had higher chances of improvements in joint mobility functions, body posture change and use of the hand. In addition, they had fewer problems with the self-care categories including washing oneself, feeding and drinking. Patients with paraplegia and longer durations of SCI experienced less significant impairments in activities and participation categories such as body transfer, transfers using devices, washing oneself and toileting.

These findings may reflect the positive effects of rehabilitation and the patients' adaptation to life with SCI. Potentially in the future, a longitudinal study design can be performed, which can provide information on factors influencing positive or negative change in functioning outcome.

In using the ICF Profile, we were able to describe the range and extent of functioning problems experienced by patients with SCI who were admitted for rehabilitation in the Disability Rehabilitation Centre Novokuznetsk. Impairments in the ICF categories of functioning and activity and participation were assessed for each patient with SCI who was included in this study. The members of the multidisciplinary team including a neurologist, a physiotherapist, a specialist on therapeutic exercises, a psychologist and a specialist on social adaptation discussed individual ICF profiles. During discussions, they defined rehabilitation goals that were feasible during a given admission. They also decided which specialists are to work with a given patient, and they defined the sequence and types of rehabilitation interventions depending on the patient's functioning profile and problems. The ICF profile improved mutual understanding between medical and non-medical personnel (for example, psychologists and adaptation specialists). The use of the ICF profile resulted in an efficient distribution of the efforts of various specialists during rehabilitation with the hospital setting. The first few days of the rehabilitation process involved patient education in terms 
Table 5 Extent of impairments/limitation in ICF categories of body functions and activities and participation according to the duration of SCI

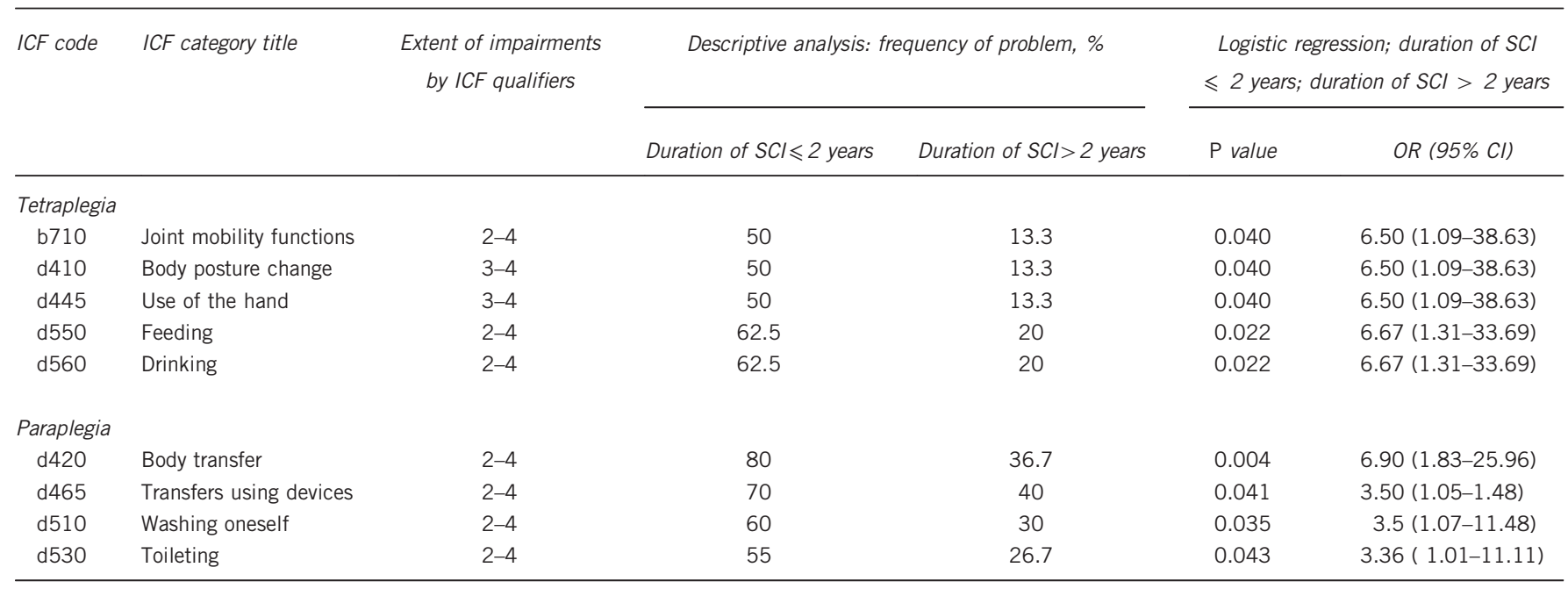

Abbreviations: $\mathrm{Cl}$, confidence interval; ICF, International Classification of Functioning, Disability and Health; OR, odds ratio.

$\mathrm{OR}>1$ indicates higher risk for problems in persons with duration of $\mathrm{SCl} \leqslant 2$ years.

Table 6 Extent of impairments/limitations in ICF categories of body functions and activities and participation according to the extent of neurological deficit

\begin{tabular}{|c|c|c|c|c|c|c|}
\hline ICF code & ICF category title & $\begin{array}{c}\text { Extent of impairments } \\
\text { by ICF qualifiers }\end{array}$ & $A / S A$ and $A / S B$ & AIS $C$ and AIS D & $\mathrm{P}$ value & OR $(95 \% C l)$ \\
\hline b620 & Urination functions & $3-4$ & 62.50 & 6.7 & 0.006 & $23.33(2.41-225.22)$ \\
\hline b640 & Sexual functions & $3-4$ & 93.75 & 33.3 & 0.004 & $30(3.03-296.6)$ \\
\hline b730 & Muscle strength functions & $3-4$ & 81.30 & 26.7 & 0.004 & $11.92(2.18-65.15)$ \\
\hline d445 & Use of the hand & $2-4$ & 87.50 & 33.3 & 0.005 & $14(2.25-87.2)$ \\
\hline \multicolumn{7}{|c|}{ Paraplegia } \\
\hline b620 & Urination functions & $1-4$ & 96.70 & 75 & 0.047 & $9.67(1.03-90.04)$ \\
\hline b640 & Sexual functions & $3-4$ & 86.78 & 35 & 0.000 & $12.11(2.98-48.82)$ \\
\hline b730 & Muscle strength functions & $3-4$ & 86.70 & 45 & 0.002 & $7.94(2.01-31.34)$ \\
\hline
\end{tabular}

Abbreviations: AIS, American Spinal Injury Association Impairment Scale; Cl, confidence interval; ICF, International Classification of Functioning, Disability and Health; OR, odds ratio.

$\mathrm{OR}>1$ indicates higher risk for problems in persons with AIS A or AIS B.

of self-care and the use of rehabilitation and assistive devices, as well as a consultation on the selection of those devices. We believe that this part of the work to coordinate the interaction between the members of the multidisciplinary team is essential because non-healthcare providers or specialists may not fully understand the health-related problems of patients or the goals of medical interventions. The use of ICF improves the interaction between the specialists, essential non-healthcare personnel and patients themselves, as well as the efficacy of resource utilization in the interest of patients.

This study has some weaknesses. First, the study population consisted of patients who differed widely in duration of SCI (that is, sample heterogeneity). This prevented us from exclusively describing problems experienced by the patients who were in the early postacute period of SCI. Possibly, in the future, we will be able to divide patients into groups with similar durations of SCI so that we may have a better understanding of how the impairments in functioning and activities and participation change over time and in which subgroup. Second, we did not study the environmental factors such as external support and assistive devices, which could influence the functioning level of a person with SCI. However, they represent an important aspect of functioning of patients with SCI, and we plan to look at them in our future research. Last, for more precise measurements, it is necessary to develop widely used and tested Russian versions of the relevant questionnaires. For example, we used a Russian version of SCIM (using a simple translation methodology) that had not undergone all the necessary procedures for linguistic and cross-cultural adaptation. Moreover, we can also examine outcome measures based on the International Spinal Cord Injury Data Sets, for various areas (http://www.iscos.org.uk/international-sci-data-sets).

\section{DATA ARCHIVING}

There were no data to deposit.

\section{CONFLICT OF INTEREST}

The authors declare no conflict of interest. 
1 Ivanova GE, Krylov VV, Cykunov MB, Poljaev BA (eds). Rehabilitation of Patients with Spinal Cord Injury. Moscow books and carto-lithography, Moscow, 2010, p 640 (in Russian).

2 Kosichkin MM, Grishina LP, Shapiro DM. Disability caused by traumatic spinal cord injury, medical and social evaluation and rehabilitation. Med Soc Eval Rehabil 1999; 1: 9-15.

3 Barinov AN, Kondakov EN. Clinical and statistical description of acute spinal trauma. Spine Surg 2010; 4: 15-18.

4 Morozov IN, Mlyavych SG. Epidemiology of spinal trauma: a review. Med Anthol 2011; 4: 157-159.

5 Hagen EM, Lie SA, Rekand T, Gilhus NE, Gronning M, Hagen EM et al. Mortality after traumatic spinal cord injury: 50 years of follow-up. J Neurol Neurosurg Psychiatry 2010; 81: 368-373.

6 Rauch A, Cieza A, Stucki G How to apply the International Classification of Functioning and Health (ICF) for rehabilitation management in clinical practice. Eur J Physiother Rehabil Med 2008; 44: 329-342.

7 ICF. International Classification of Functioning, Disability and Health. World Health Organization: Geneva, 2001, p 299.

8 Junusov FA, Kochubej AV. Integration tools of International Classification of Functioning, Disability and Health and actual model of rehabilitation process. Bulletin of Neurology 2009; 4: 22-26.

9 Order by the Ministry of Labor of the Russian Federation №664n dated 29 September 2014 "On the classifications and criteria used in medical and social evaluation by the federal institutions for medical and social evaluation" (in Russian).

10 Cieza A, Boldt C, Ballert CS, Eriks-Hoogland I, Bickenbach JE, Stucki G Setting up a cohort study on functioning: deciding what to measure. Am J Phys Med Rehabil 2011; 90: 17-28.

11 Kirchberger I, Cieza A, Biering-Sørensen F, Baumberger M, Charlifue S, Post MW et al. ICF core sets for individuals with spinal cord injury in the early post-acute context. Spinal Cord 2010; 48: 297-304.

12 Cieza A, Kirchberger I, Biering-Sørensen F, Baumberger M, Charlifue S, Post MW et al. ICF core sets for individuals with spinal cord injury in the long-term context. Spinal Cord 2010; 48: 305-312.

13 Post MW, Brinkhof MW, von Elm E, Boldt C, Brach M, Fekete C et al. Design of the Swiss Spinal Cord Injury Cohort Study. Am J Phys Med Rehabil 2011; 90: 5-16.

14 Kirshblum SC, Waring W, Biering-Sorensen F, Burns SP, Johansen M, Schmidt-Read M et al. Reference for the 2011 revision of the International Standards for Neurological Classification of Spinal Cord Injury. J Spinal Cord Med 2011; 34: 547-554.

15 Bohannon R, Smith M Interrater reliability of a modified Ashworth Scale of muscle spasticity. Phys Ther 1987; 67: 206-207.

16 Weiss M, Zembaty A Physiotherapy. Medicine, Moscow, 1986, p 496 (in Russian).

17 Pressure ulcer treatment strategies: comparative effectiveness. comparative effectiveness reviews, no. 90; AHRQ 2013; 13-EHCO03-1-EF.
18 Spooren AI, Janssen-Potten YJ, Post MW, Kerckhofs E, Nene A, Seelen HA Measuring change in arm hand skilled performance in persons with a cervical spinal cord injury: responsiveness of the Van Lieshout Test. Spinal Cord 2006; 44: 772-779.

19 Itzkovich M, Gelernter I, Biering-Sorensen F, Weeks C, Laramee MT, Craven BC et al. The Spinal Cord Independence Measure (SCIM) version III: Reliability and validity in a multi-center international study. Disabil Rehabil 2007; 29: 1926-1933.

20 Kalpakjian CZ, Scelza WM, Forchheimer MB, Toussaint LL Preliminary reliability and validity of a Spinal Cord Injury Secondary Conditions Scale. J Spinal Cord Med 2007; 30: 131-139.

21 Nwankwo OE, Uche EO Epidemiological and treatment profiles of spinal cord injury in southeast Nigeria. Spinal Cord 2013; 51: 448-452.

22 Aito S, Tucci L, Zidarich V, Werhagen L Traumatic spinal cord injuries: evidence from 30 years in a single centre. Spinal Cord 2014; 52: 268-271.

23 Karacan I, Koyuncu H, Pekel O, Sümbüloglu G, Kirnap M, Dursun H et al. Traumatic spinal cord injuries in Turkey: a nation-wide epidemiological study. Spinal Cord 2000; 38: 697-701.

24 Chen HY, Chen SS, Chiu WT, Lee LS, Hung Cl, Hung $\mathrm{CL}$ et al. A nationwide epidemiological study of spinal cord injury in geriatric patients in Taiwan. Neuroepidemiology 1997; 16: 241-247.

25 Martins F, Freitas F, Martins L, Dartigues JF, Barat M Spinal cord injuries epidemiology in Portugal's central region. Spinal Cord 1998; 36: 574-578.

26 Wang HF, Yin ZS, Chen Y, Duan ZH, Hou S, He J Epidemiological features of traumatic spinal cord injury in Anhui Province, China. Spinal Cord 2013; 51: 20-22.

27 Nijendijk JH, Post MW, van Asbeck FW Epidemiology of traumatic spinal cord injuries in The Netherlands in 2010. Spinal Cord 2014; 52: 258-263.

28 Katoh S, Enishi T, Sato N, Sairyo K High incidence of acute traumatic spinal cord injury in a rural population in Japan in 2011 and 2012: an epidemiological study. Spinal Cord 2014; 52: 264-267.

29 Nas K, Yazmalar L, Sah V, Aydın A, Öneş K Rehabilitation of spinal cord injuries. World J Orthop 2015; 6: 8-16.

30 Kirchberger I, Biering-Sørensen F, Charlifue S, Baumberger M, Campbell R, Kovindha A et al. Identification of the most common problems in functioning of individuals with spinal cord injury using the International Classification of Functioning, Disability and Health. Spinal Cord 2010; 48: 221-229.

31 Herrmann KH, Kirchberger I, Biering-Sørensen F, Cieza A Differences in functioning of individuals with tetraplegia and paraplegia according to the International Classification of Functioning, Disability and Health (ICF). Spinal Cord 2011; 49: 534-543.

32 Krassioukov A, Biering-Sørensen F, Donovan W, Kennelly M, Kirshblum S, Krogh K et al. Autonomic Standards Committee of the American Spinal Injury Association/ International Spinal Cord Society. International standards to document remaining autonomic function after spinal cord injury. J Spinal Cord Med 2012; 35: 201-210.

33 Anderson KD Targeting recovery: priorities of the spinal cord-injured population. J Neurotrauma 2004; 21: 1371-1383. 